ano 16 - n. 63। janeiro/março - 2016

Belo Horizonte I p. 1-262 I ISSN 1516-3210

A\&C - R. de Dir. Administrativo \& Constitucional

Revista de Direito ADMINISTRATIVO \& CONSTITUCIONAL

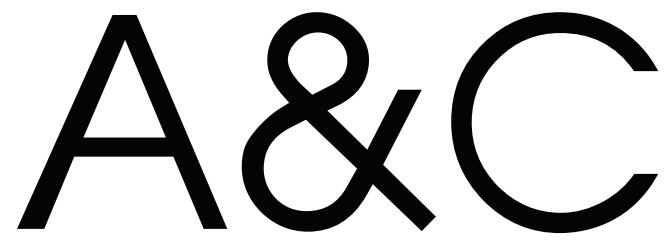




\section{A\&C - REVISTA DE DIREITO ADMINISTRATIVO \& CONSTITUCIONAL}

IPDA

Instituto Paranaense

de Direito Administrativo
ROMEU DELPE

BACELLAR

(c) 2016 Editora Fórum Ltda.

Todos os direitos reservados. É proibida a reprodução total ou parcial, de qualquer forma ou por qualquer meio eletrônico ou mecânico, inclusive através de processos xerográficos, de fotocópias ou de gravação, sem permissão por escrito do possuidor dos direitos de cópias (Lei no 9.610, de 19.02.1998).

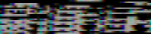

Luís Cláudio Rodrigues Ferreira

Presidente e Editor

Av. Afonso Pena, 2770 - 15a andar - Savassi - CEP 30130-012 - Belo Horizonte/MG - Brasil - Tel.: 08007043737 www.editoraforum.com.br / E-mail: editoraforum@editoraforum.com.br

Impressa no Brasil / Printed in Brazil / Distribuída em todo o Território Nacional

Os conceitos e opiniões expressas nos trabalhos assinados são de responsabilidade exclusiva de seus autores.

\begin{tabular}{|c|c|}
\hline A246 & $\begin{array}{l}\text { A\&C : Revista de Direito Administrativo \& } \\
\text { Constitucional. - ano 3, n. 11, (jan./mar. } \\
\text { 2003)- . - Belo Horizonte: Fórum, 2003- }\end{array}$ \\
\hline & Trimestral \\
\hline & $\begin{array}{l}\text { Ano 1, n. 1, } 1999 \text { até ano 2, n. 10, } 2002 \text { publicada } \\
\text { pela Editora Juruá em Curitiba }\end{array}$ \\
\hline & $\begin{array}{l}\text { 1. Direito administrativo. 2. Direito constitucional. } \\
\text { I. Fórum. }\end{array}$ \\
\hline & $\begin{array}{l}\text { CDD: } 342 \\
\text { CDU: } 342.9\end{array}$ \\
\hline
\end{tabular}

Coordenação editorial: Leonardo Eustáquio Siqueira Araújo Capa: Igor Jamur

Projeto gráfico e diagramação: Walter Santos

\section{Periódico classificado no Estrato A1 do Sistema Qualis da CAPES - Área: Direito.}

Revista do Programa de Pós-graduação do Instituto de Direito Romeu Felipe Bacellar (Instituição de Pesquisa e Pós-Graduação), em convênio com o Instituto Paranaense de Direito Administrativo (entidade associativa de âmbito regional filiada ao Instituto Brasileiro de Direito Administrativo). A linha editorial da $A \& C$ - Revista de Direito Administrativo \& Constitucional segue as diretrizes do Programa de Pós-Graduação do Instituto de Direito Romeu Felipe Bacellar em convênio com o Instituto Paranaense de Direito Administrativo. Procura divulgar as pesquisas desenvolvidas na área de Direito Constitucional e de Direito Administrativo, com foco na questão da efetividade dos seus institutos não só no Brasil como no direito comparado, com ênfase na questão da interação e efetividade dos seus institutos, notadamente América Latina e países europeus de cultura latina.

A publicação é decidida com base em pareceres, respeitando-se o anonimato tanto do autor quanto dos pareceristas (sistema double-blind peer review).

Desde o primeiro número da Revista, $75 \%$ dos artigos publicados (por volume anual) são de autores vinculados a pelo menos cinco instituições distintas do Instituto de Direito Romeu Felipe Bacellar.

A partir do volume referente ao ano de 2008 , pelo menos $15 \%$ dos artigos publicados são de autores filiados a instituições estrangeiras.

Esta publicação está catalogada em:

- Ulrich's Periodicals Directory

- RVBI (Rede Virtual de Bibliotecas - Congresso Nacional)

- Library of Congress (Biblioteca do Congresso dos EUA)

A\&C - Revista de Direito Administrativo \& Constitucional realiza permuta com as seguintes publicações: - Revista da Faculdade de Direito, Universidade de São Paulo (USP), ISSN 0303-9838

- Rivista Diritto Pubblico Comparato ed Europeo, ISBN/EAN 978-88-348-9934-2 
Diretor-Geral

Romeu Felipe Bacellar Filho

Diretor Editorial

Paulo Roberto Ferreira Motta

Editores Acadêmicos Responsáveis

Daniel Wunder Hachem

Ana Cláudia Finger

Assessor Editorial

Felipe Klein Gussoli

\section{Conselho Editorial}

Adilson Abreu Dallari (PUC-SP) Juan Pablo Cajarville Peluffo (Universidad de La República - Uruguai) ardo Schier (Instituto Bacellar) Justo J. Reyna (Universidad Nacional del Litoral - Argentina)

Alice Gonzalez Borges (UFBA) Juarez Freitas (UFRGS)

Carlos Ari Sundfeld (FGV-SP) Luís Enrique Chase Plate (Universidad Nacional de Asunción - Paraguai)

Carlos Ayres Britto (UFSE) Marçal Justen Filho (UFPR)

Adriana da Costa Ricardo Schier (Instituto Bacellar)
Alice Gonzalez Borges (UFBA)

Marcelo Figueiredo (PUC-SP)

Márcio Cammarosano (PUC-SP)

Carlos Delpiazzo (Universidad de La República - Uruguai) Cármen Lúcia Antunes Rocha (PUC Minas) Célio Heitor Guimarães (Instituto Bacellar) Celso Antônio Bandeira de Mello (PUC-SP) Clèmerson Merlin Clève (UFPR) Clovis Beznos (PUC-SP) Edgar Chiuratto Guimarães (Instituto Bacellar) Maria Cristina Cesar de Oliveira (UFPA)

Nelson Figueiredo (UFG)

Odilon Borges Junior (UFES)

Pascual Caiella (Universidad de La Plata - Argentina)

Emerson Gabardo (UFPR)

Paulo Eduardo Garrido Modesto (UFBA)

Paulo Henrique Blasi (UFSC)

Enrique Silva Cimma (Universidad de Chile - Chile) Eros Roberto Grau (USP)

Irmgard Elena Lepenies (Universidad Nacional del Litoral - Argentina) de La Coruña - Espanha)

Pedro Paulo de Almeida Dutra (UFMG)

Regina Maria Macedo Nery Ferrari (UFPR)

Rogério Gesta Leal (UNISC)

Rolando Pantoja Bauzá (Universidad Nacional de Chile - Chile)

Sergio Ferraz (PUC-Rio)

Valmir Pontes Filho (UFCE)

José Eduardo Martins Cardoso (PUC-SP)

José Luís Said (Universidad de Buenos Aires - Argentina) José Mario Serrate Paz (Universidad de Santa Cruz - Bolívia)

Yara Stroppa (PUC-SP)

\section{Homenagem Especial}

Guillermo Andrés Muñoz (in memoriam) Jorge Luís Salomoni (in memoriam) Julio Rodolfo Comadira (in memoriam) Lúcia Valle Figueiredo (in memoriam)

Manoel de Oliveira Franco Sobrinho (in memoriam) Paulo Neves de Carvalho (in memoriam) 


\title{
Instrumentos de la lucha contra la corrupción en Colombia: de la ultima ratio a la ausencia de razón
}

\section{Andrés Fernando Ospina Garzón}

Docente-Investigador de la Universidad Externado de Colombia (Bogotá, Colombia). Doctor en Derecho de la Universidad de París II, Panthéon-Assas. E-mail: <andres.ospina@uexternado. edu.co>.

\begin{abstract}
Resumen: A pesar de que la corrupción no sea un fenómeno exclusivo de Colombia, el país ha luchado desde distintos ángulos para combatirla. La lógica indicaría que los instrumentos deben prioritariamente propender, en primer lugar, por la prevención de actos de corrupción, en segundo lugar, por retrotraer sus efectos negativos y, en tercer lugar, por sancionar a los corruptos. Esta gradación de los instrumentos resulta de la ultima ratio propia de la sanción penal. Sin embargo, la lucha colombiana contra la corrupción ha puesto en evidencia una inversión de la lógica, en la que la sanción penal se convierte en la prima ratio y se confía ciega e ingenuamente en su poder disuasivo, en un país donde los corruptos prefieren pagar penas de prisión, a condición de asegurarse el disfrute posterior de los frutos del delito. En realidad, los instrumentos propios del derecho administrativo, a partir de su adecuada configuración y utilización, pueden disminuir considerablemente los niveles de corrupción en Colombia, al tiempo que contribuyen a la eficacia de la actividad pública.
\end{abstract}

Palabras-clave: Corrupción. Colombia. Derecho administrativo. Derecho penal. Derecho disciplinario.

Sumario: 1 Introducción - 2 Perseguir - $\mathbf{3}$ Revertir - 4 Prevenir - 5 Conclusión - Referencias

\section{Introducción}

La separación entre la moral, la ética y el derecho guió durante mucho tiempo los estudios científicos de los juristas; el purismo los obligaba a desdeñar cuestiones no positivas. Pero la separación fue, desde el principio, artificial, ya que el derecho, como producto humano, resulta de valoraciones, concepciones éticas, escogencias y priorizaciones que privilegian ciertas finalidades, ciertos valores. Es por esto que la situación del derecho de un país refleja su escala de valores, el momento de evolución, la lógica de las relaciones sociales. A partir de esto, un estudio de los instrumentos diseñados por el derecho colombiano para combatir la corrupción puede radiografiar una sociedad en la que la corrupción se entronizó en el poder público, determinó, en gran medida, la ineficacia de la acción pública en pro del desarrollo social y permeó incluso los mecanismos de control. Además, un análisis en perspectiva del sistema jurídico de lucha contra la corrupción mostrará una inversión 
de la lógica de los instrumentos jurídicos donde la sanción penal, teóricamente ultima ratio, se ha convertido en la prima ratio. El balance mostrará visos de esperanza en la lucha contra la corrupción, pero a la vez, un manejo desordenado de dichos instrumentos, es decir, no sólo una ultima que se convirtió en prima ratio, sino una ausencia de razón.

El problema de la corrupción en Colombia no es vano: en razón de la corrupción el "Estado deja de percibir cuarenta billones en impuestos", ${ }^{1}$ alrededor de 53.200.000.000 reales. Según cifras de la Contraloría general de la República, el grupo empresarial Nule, empresa familiar artífice de uno de los más grandes escándalos de corrupción en el país de los últimos años, ${ }^{2}$ relacionado con una cantidad importante de obras de infraestructura contratadas con la empresa familiar ${ }^{3}$ ha determinado unas pérdidas financieras para el Estado de alrededor de 2.390.000 reales por grandes obras de infraestructura. Pero el problema no solamente es financiero o, de manera más precisa, no se puede medir solamente en términos económicos: la corrupción es una de las principales razones por las que, en Colombia, sigan existiendo vastas zonas del país sin acceso a servicios públicos esenciales, una parte considerable de la niñez sufra de desnutrición e, incluso muera por la falta de alimentos. ${ }^{4}$ La corrupción es causa del atraso y determinante de la ineficacia pública. ${ }^{5}$ Por esta razón, el análisis de los factores tomados en consideración por el programa de las Naciones Unidas para el desarrollo, tales como la expectativa de vida, el acceso a la escuela y a servicios de salud, haya determinado que Colombia obtenga, en 2014, un 0,711 en el HDI (Human development index) y se encuentre en el lugar 98 del escalafón mundial, en materia de desarrollo humano, mientras que Brasil ocupa el lugar $79^{6}$ y el país latinoamericano mejor ubicado sea Chile, en el lugar 41.

1 TENGO a los mejores investigadores. El Espectador, 8 oct. 2013. Disponible en: <http://www.elespectador. com/noticias/nacional/tengo-los-mejores-investigadores-articulo-439130>. Acceso en: 15 oct. 2013.

2 En 1992, Colombia padeció una crisis energética debido al fenómeno del niño. Para generar electricidad y, palear la crisis, el Gobierno contrató la compra de varias barcazas generadoras de energía que, al no ser técnicamente compatibles con el sistema eléctrico nacional, no pudieron ser utilizadas. La compra, realizada sin garantías adecuadas que respondieran por la totalidad del gasto público, tuvo un costo de 12.000 .000 de dólares estadounidenses (MEJíA MAZUERA, Jaime. Barcazas no fueron bien aseguradas. El Tiempo, 10 feb. 1993. Disponible en: <http://www.eltiempo.com/archivo/documento/MAM-39133>).

3 Una explicación didáctica del caso conocido como "carrusel de la contratación" puede consultarse en LA CAÍDA del imperio de los Nule. El Tiempo. Disponible en: <http://www.eltiempo.com/Multimedia/infografia/nule/>.

4 Según un informe realizado por UNICEF y el Instituto colombiano de bienestar familiar, al año mueren en Colombia 5000 niños, por causa de la desnutrición (CINCO mil niños mueren desnutridos en Colombia cada año. Semana, 27 mayo 2009. Disponible en: <http://www.semana.com/nacion/problemas-sociales/articulo/ cinco-mil-ninos-mueren-desnutridos-colombia-cada-ano/103513-3>).

5 “La gran corrupción ha afectado el acceso al agua, a la tenencia de una vivienda digna, al medio ambiente sano, a la educación, a la salvaguarda de la vida de las personas por parte de las autoridades, a la movilización, al trabajo, etc., y, sobre todo, en Colombia, a la salud, víctima como ninguno de los atropellos y las componendas de los corruptos" (SILVA GARCÍA, Germán. Introducción: La corrupción a nivel mundial. In: MORELLI RICO, Sandra et alli (Coords.). Corrupción, flagelo mundial. Bogotá: Contraloría General de la República, 2013. p. 20. t. II).

6 DOWNLOAD 2015 Human Development Statistical Tables. United Nations Development Programme. Disponible en: <http://hdr.undp.org/en/data>. 
La corrupción genera desconfianza de la población frente al Estado, desinterés por los asuntos públicos e incluso apatía e indiferencia frente a la corrupción pública por una especie de acostumbramiento al mal permanente. La corrupción es el cáncer que provoca el divorcio entre la sociedad y sus gobernantes; ${ }^{7}$ cuando hablamos de "corrupción estamos tratando de la descomposición del propio sistema". ${ }^{8}$

El problema es global. Colombia suscribió la Convención de las Naciones Unidas contra la corrupción ${ }^{9}$ que propugnó, entre otras medidas, por la creación en la legislación interna del delito de soborno transnacional, ${ }^{10}$ la Convención interamericana contra la corrupción, ${ }^{11}$ e incluso la ONG Transparencia internacional establece periódicamente un escalafón de corrupción por países conocido como el Corruption perception index que, en el 2014, situó a Colombia en el puesto 94, al lado de Egipto, Liberia y Panamá, mientras que Brasil ocupó el lugar 69, puesto compartido con Grecia, Italia, Rumania y Senegal. ${ }^{12}$ Los países latinoamericanos mejor calificados fueron Chile y Uruguay, en el lugar 21 y el peor calificado fue Venezuela, en el puesto 161, aunque, “En la dictadura no hay propiamente casos de corrupción, sino que ella misma es la corrupción institucionalizada". ${ }^{13}$

El problema no es reciente. Sin necesidad de acudir a fuentes que mostrarian casos de corrupción en la antigua Grecia o en Roma, el derecho indiano, es decir, el conjunto de normas aplicables a los territorios colonizados por España en América, da cuenta de una serie de requisitos para acceder a los cargos públicos, dentro de las que

7 “[...] el Estado enfrenta un cáncer. Es una enfermedad, que está llevando al país hacia la muerte. Es un tumor que está propiciado un divorcio, cada vez mayor, entre los ciudadanos y sus autoridades. Encuestas recientes muestran la sensación inmensa que tienen la mayoría de los colombianos acerca del grado de corrupción que impera en las instituciones públicas. Así mismo, es un hecho, que muy poco se ha hecho realmente para sancionar a quienes se han dedicado a saquear el Estado. Como tuvo la oportunidad de demostrarlo, el Senador Eduardo Pizano, en el mes de octubre de 1992, en ese momento, en las cárceles colombianas, no se encontraba un solo condenado por enriquecimiento ilícito" (EXPOSICIÓN de motivos. Alcaldía Bogotá. Disponible en: <http://www.alcaldiabogota.gov.co/sisjur/normas/Norma1.jsp?i=10593\#0>. Acceso en: 20 oct. 2012).

8 CONDE-PUMPIDO TOURÓN, Cándido. El poder público no atiende al interés general. In: MORELLI RICO, Sandra et alli (Coords.). Corrupción, flagelo mundial. Bogotá: Contraloría General de la República, 2013. p. 34. t. II.

9 Convención para combatir el soborno de funcionarios públicos extranjeros en las transacciones comerciales de la Organización para para la Cooperación y el desarrollo económico (OCDE). 17 dic. 1997 firmada en Convención para combatir el soborno de funcionarios públicos extranjeros en las transacciones comerciales de la Organización para para la Cooperación y el desarrollo económico (OCDE). 17 dic. 1997 París.

10 “Cada parte adoptará las medidas necesarias para establecer en su legislación como un delito, para cualquier persona, ofrecer, prometer o dar intencional e ilegalmente cualquier cosa de valor pecuniario u otras ventajas, sea en forma directa o mediante intermediarios, a un funcionario público extranjero, para ese funcionario o para otra persona, a fin de conseguir que tal funcionario realice u omita cualquier acto en el cumplimiento de sus deberes oficiales en orden a obtener o conservar un negocio u otras ventajas impropias en el contexto de un negocio internacional".

11 Firmada en Caracas el 29 de marzo de 1996 y ratificada por los miembros de la OEA.

12 CORRUPTION Perceptions Index 2014: Results. Transparency International. Disponible en: <https://www. transparency.org/cpi2014/results>.

13 GALÁN GALÁN, Alfredo. Buena administración e instrumentos jurídicos de la lucha contra la corrupción. La experiencia española In: MORELLI RICO, Sandra et alli (Coords.). Corrupción, flagelo mundial. Bogotá: Contraloría General de la República, 2013. p. 36. t. II. 
se destacan la de ser virtuoso y pertenecer a la clase media, con un patrimonio propio suficiente para no tener tentaciones. ${ }^{14}$ La historia del derecho indiano demuestra que se vendían los cargos públicos ${ }^{15} \mathrm{e}$, incluso, mecanismos contra la corrupción como el juicio de residencia, realizado para controlar al funcionario a la dejación de las funciones, fueron objeto de corrupción. ${ }^{16}$

Si el problema es mundial, antiguo y permanente, pareciera que la lucha contra la corrupción debe buscar erradicarla, pero conformarse con su reducción significativa y progresiva. Para alcanzar este objetivo, el orden jurídico, en su conjunto, ofrece mecanismos que se mezclan convenientemente y, este entrelazamiento, determina el éxito de la estrategia. La preeminencia de mecanismos de derecho penal, frente a mecanismos administrativos que propendan por la reducción de la oportunidad para la corrupción y la generación de un ambiente hostil a la corrupción es signo de un sistema arcaico frente al problema. Durkhein clasificaba, en efecto, las sociedades en aquellas de derecho penal, de derecho administrativo y de derecho contractual: "En las sociedades primitivas [...] el derecho es enteramente penal [...]".17 “La historia muestra, en efecto, que, de una manera regular, el derecho administrativo se encuentra más desarrollado en las sociedades que pertenecen a un tipo más elevado; por el contrario, mientras más nos vamos a los orígenes, éste es más rudimentario". ${ }^{18}$ La evolución social, de la mano del derecho, determina no el abandono completo del derecho penal, sino que éste es relegado a ser la última opción frente a los problemas sociales, es decir, la ultima ratio. Cuando frente al problema, la primera respuesta es la sanción penal, la regresión hacia el arcaísmo se hace evidente. Este panorama de los instrumentos utilizados en Colombia para la lucha contra la corrupción, en los últimos años, permitirá un análisis crítico del conjunto del esquema jurídico en la materia.

Los instrumentos actuales en la lucha contra la corrupción fueron diseñados en los últimos cinco gobiernos. Un breve recuento lo mostrará, pero en el cuerpo del escrito se desarrollará. Así, durante el Gobierno de César Gaviria Trujillo (1990-1994)

14 Cf. MARILUZ-URQUIJO, José-María. El agente de la administración pública en Indias. Buenos Aires: Instituto Internacional de Historia del Derecho Indiano e Instituto de Investigaciones de Historia del Derecho, 1998. p. 125.

15 PARRY, John H. The sale of public offices in Spanish indies under the Habsburgs. Berkeley; Los Angeles: University of California Press, 1953. Un documentado estudio del sistema de venta de cargos puede consultarse en SANZ TAPIA, Ángel. La venta de oficios de hacienda en la Audiencia de Quito (1650-1700). Revista de Indias, v. XIII, n. 229, p. 633-648, 2003.

16 Puede verse: PIETSCHMANN, Herbert. Burocracia y corrupción en la Hispanoamérica colonial: Una aproximación tentativa. Editorial Nova Americana, Turín, n. 5, p. 11-37, 1982. Y, del mismo autor: Corrupción en las Indias españolas. Revisión de un debate. In: GONZÁLEZ JIMÉNEZ, Manuel (Coord.). Instituciones y corrupción en la historia. Valladolid: Universidad de Valladolid, 1998. p. 31-52.

17 DURKHEIM, Emile. De la division du travail social. Livre premier. p. 78. Disponible en: <http://classiques. uqac.ca/classiques/Durkheim_emile/division_du_travail/division_travail_1.pdf>.

18 DURKHEIM, Emile. De la division du travail social. Livre premier. p. 119. Disponible en: <http://classiques. uqac.ca/classiques/Durkheim_emile/division_du_travail/division_travail_1.pdf>. 
se reformó el Código penal, se crearon las oficinas de control interno, se expidió la ley 80 de 1993 - Estatuto de contratación estatal- y se creó la extinción de dominio por corrupción. Durante el Gobierno de Ernesto Samper Pizano (1994-1998), presidente acusado, investigado y exonerado de manera controversial por la financiación de su campaña presidencial con dineros provenientes del narcotráfico, se expidió el primer Estatuto anticorrupción - ley 190 de 1995 "por la cual se dictan normas tendientes a preservar la moralidad en la Administración Pública y se fijan disposiciones con el fin de erradicar la corrupción administrativa". Bajo el Gobierno de Andrés Pastrana Arango (1998-2002) se crea el Programa presidencial de lucha contra la corrupción, se crea el Sistema de información de la contratación estatal SICE, como sistema de precios de referencia para el apoyo de la Contraloría en su labor de control -Ley 598 de 2000 -. En los Gobiernos de Álvaro Uribe Vélez (2002-2006 y 2006-2010), cuyos ministros de Agricultura, del interior y de salud fueron condenados penalmente por actos de corrupción, ${ }^{19}$ el primero en materia de la entrega irregular de subsidios ${ }^{20}$ y los dos otros en la compra de los votos para permitir la reelección del Presidente, en un caso en el que se vio al "Estado sobornando al propio Estado" 21 y en el que el propio Presidente de la República participó, ${ }^{22}$ al dar las instrucciones a los ministros de realizar los ofrecimientos por las que serían posteriormente condenados, ${ }^{23}$ se ratificó la Convención internacional de las Naciones Unidas de lucha contra la corrupción. Por su parte, en el Gobierno de Juan Manuel Santos (2010-2014 y 2014-2018) se expidió la ley 1474 de 2011, Estatuto anticorrupción y se expidió el Decreto-ley 019 de 2012, antitrámites que, entre otras cosas, suprimió el sistema SICE.

Este rápido panorama permite establecer una clasificación de los instrumentos, a partir del criterio de su preeminencia en el ordenamiento jurídico colombiano: aquellos que pretenden perseguir (I) a los corruptos para sancionarlos, los que

19 MALA hora del gabinete Uribe. El Espectador, 30 jul. 2011 Disponible en: <http://www.elespectador.com/ noticias/judicial/mala-hora-del-gabinete-uribe-articulo-288245>.

20 CORTE condenaa Arias a 17 años de cárcel; está prófugo en EE. UU. El Tiempo, 17 jul. 2014. Disponible en: <http:// www.eltiempo.com/politica/justicia/condena-a-andres-felipe-arias-por-agro-ingreso-seguro/14260975>.

21 Corte Suprema de Justicia, Sala Penal, Sentencia que condenó a los ex ministros Sabas Pretelt y Diego Palacio, y al exsecretario de Casa de Nariño, Alberto Velásquez, por su participación en los cohechos que permitieron la reforma constitucional que abrió paso a la reelección de Álvaro Uribe.

22 La Sentencia de la Corte suprema de justicia precisa que "conforme a lo probado en este asunto, los hechos [...] evidencian que Alberto Velásquez, al igual que los otros dos procesados, hizo suyos los ofrecimientos hechos a Yidis Medina Padilla por el entonces Presidente de la República, en la medida en que le especificó a la congresista los cargos disponibles en el Magdalena Medio [...] comprometiéndose a hablar con los ministros del ramo para concretar los nombramientos correspondientes".

23 La misma sentencia explica que "En el análisis de las piezas que constituyen el voluminoso expediente, la Corte Suprema de Justicia determinó cómo, siguiendo instrucciones del entonces presidente Álvaro Uribe Vélez, el exsecretario General de la Presidencia y los exministros de Protección Social y del Interior y de Justicia dispusieron del poder que les conferían sus altos cargos para pagar, con una serie nombramientos, el voto favorable de la exrepresentante Yidis Medina y la ausencia de Teodolindo Avendaño en la votación de aquella madrugada" (ORDEN de captura a tres altísimos funcionarios del gobierno Uribe. Semana, 15 abr. 2015. Disponible en: <http://www.semana.com/nacion/articulo/ sabas-pretelt-diego-palacio-alberto-velasquez-condenados-por-yidispolitica/424181-3>). 
buscan revertir (II) los efectos de la corrupción y aquellos que se dirigen a prevenir (III) los actos de corrupción. Aunque parezca lógico, la prevención administrativa no es la prima ratio sino la ultima, en un esquema donde la venganza institucionalizada prima.

\section{Perseguir}

\subsection{La investigación de los actos de corrupción}

Perseguir la corrupción para alcanzarla, pero nunca adelantarla. Para esto, es necesaria la investigación adecuada de los comportamientos como medida de instrucción previa a la sanción. El ejercicio del ius puniendi, en Colombia, respecto de la corrupción, se comparte en materia penal y en materia disciplinaria, aunque, en realidad, las distintas normas anticorrupción han establecido más instancias de investigación o de denuncia de actos de corrupción. En materia de investigación penal, la fiscalía colombiana dispone de una fiscalía especializada en la persecución de los delitos relacionados con la corrupción. El Estatuto anticorrupción de 1995 dotó a la fiscalía de un instrumento eficaz en la lucha contra este flagelo que consiste en la posibilidad de negociar acuerdos de beneficios ${ }^{24}$ con los corruptos que delaten a sus determinadores o cómplices y permitan el desmantelamiento de la mafias de corrupción. ${ }^{25}$ Por su parte, el Estatuto anticorrupción de 2011 autorizó la realización de operaciones encubiertas que permitan a un agente público infiltrarse en las organizaciones criminales, actuar como agente encubierto copartícipe del delito, sin que pueda ser sancionado penalmente (Art. 36 de la ley 1474 de 2011).

En materia disciplinaria, el poder de sanción es atribuido a las oficinas de control interno disciplinario, ubicadas en cada entidad pública, pero sin instrumentos orgánicos ni funcionales suficientes para luchar contra la corrupción ${ }^{26}$ Por esta razón, la Procuraduría general de la Nación dispone de un poder preferente que le permite desplazar a las oficinas de control interno disciplinario de cada entidad pública y el Estatuto anticorrupción de 1995 (ley 190) creó una viceprocuraduría contra la corrupción. Por su parte, aunque la función esencial de las contralorías no sea la de sancionar, si en el ejercicio de su función de control del gasto público encuentran situaciones

\footnotetext{
24 En un español jurídico mal hablado por penalistas colombianos, este tipo de beneficios se conoce como "principio de oportunidad". En realidad el principio de oportunidad no son los beneficios en sí mismos, sino el postulado que inspira y permite dichas negociaciones.

25 'La corrupción es un 'matrimonio' entre un corruptor y el corrupto. En tal sentido generalmente no existen testigos, y las dos partes quedan comprometidas ante la ley penal" (EXPOSICIÓN de motivos. Alcaldía Bogotá. Disponible en: <http://www.alcaldiabogota.gov.co/sisjur/normas/Norma1.jsp?i=10593\#0>. Acceso en: 20 oct. 2012).

26 "sus oficinas de control disciplinario interno no tienen la fuerza suficiente para enfrentar un enemigo tan poderoso como la corrupción" (TENGO a los mejores investigadores. El Espectador, 8 oct. 2013. Disponible en: <http://www.elespectador.com/noticias/nacional/tengo-los-mejores-investigadores-articulo-439130>. Acceso en: 15 oct. 2013).
} 
reprochables, deben comunicar la situación a las autoridades tanto penales, como administrativas (disciplinarias). También, se creó una Unidad administrativa especial - Agencia del inspector general de tributos, rentas y contribuciones parafiscales, en el Ministerio de Hacienda, ${ }^{27}$ para recibir quejas investigar y sancionar actos de corrupción en materia de impuestos. Esta agencia pretende el desmantelamiento de las mafias de corrupción tributaria.

Finalmente, los estatutos anticorrupción han situado deberes especiales de denuncia en cabeza de los particulares que ejerzan funciones de contadores o de revisores fiscales. Así, según el estatuto anticorrupción de 1995, los revisores fiscales de los contratistas del Estado deben vigilar que no se realicen pagos a ningún servidor público y que los estados financieros reflejen la realidad de los ingresos y pagos. También se encuentran en la obligación de colaborar con quien realice labores de interventoría o supervisión del contrato. ${ }^{28}$ Por su parte, el estatuto anticorrupción de 2011 adicionó una causal de revocatoria de la tarjeta profesional del contador público que ejerciendo la función de revisor fiscal y conociendo actos de corrupción o debiendo legalmente conocerlos, no los denuncie dentro de los seis meses siguientes. También se excluyeron de la cobertura del secreto profesional los actos de corrupción. ${ }^{29}$ El Estatuto anticorrupción de 2011 prohibió las represalias contra el servidor público que denuncia actos de corrupción y su violación se considera como una falta disciplinaria (art. 43).

\subsection{La sanción penal de la corrupción}

Las distintas modificaciones introducidas a los dispositivos penales han puesto en evidencia que la sanción penal es el instrumento preferido en Colombia en la lucha contra la corrupción: cada escándalo de corrupción termina convertido en una reforma al Código penal que amplía el ámbito de aplicación de los delitos contra la Administración pública, crea nuevos delitos, aumenta las penas de los existentes o reduce los beneficios para los corruptos. Así, el Estatuto anticorrupción de 1995 introdujo un concepto amplísimo de servidor público, aplicable para los solos efectos penales, que permite incluir a los particulares que administren dineros o recursos públicos provenientes de impuestos, tasas o contribuciones o ejerzan funciones públicas dentro del sujeto activo cualificado "el servidor público que". ${ }^{30}$ La lucha

27 TENGO a los mejores investigadores. El Espectador, 8 oct. 2013. Disponible en: <http://www.elespectador. com/noticias/nacional/tengo-los-mejores-investigadores-articulo-439130>. Acceso en: 15 oct. 2013.

28 Art. 80 de la ley 190 de 1995. El deber de entregar informes a los interventores fue declarado constitucional por la sentencia C-538 de 1997 de la Corte constitucional.

29 Art. 7 de la ley 1474 de 2011, que modificó el artículo 26 de la ley 43 de 1990 al introducir un numeral 5, con una nueva causal de revocatoria de la tarjeta profesional.

30 Artículo 18․- Modifícase el artículo 63 del Código Penal así: “Artículo 63‥- Servidores Públicos. Para todos los efectos de la ley penal, son servidores públicos los miembros de la Corporaciones Públicas, los empleados 
contra la corrupción se guió en adelante por criterios materiales, no solamente orgánicos. ${ }^{31}$ También el Estatuto anticorrupción de 2011 dedica una parte muy importante a asuntos penales. En efecto, restringió la posibilidad de otorgar beneficios y subrogados penales respecto de las personas que hayan sido condenados por delitos relacionados con la corrupción (Art. 13 de la ley 1474). Igualmente amplió el término de prescripción en la mitad para investigar delitos dolosos cometidos por servidores públicos o particulares que ejercen funciones públicas (art. 14). Se crearon tres nuevos delitos relacionados con actos de corrupción, que vinieron completar la lista ya larga: el tráfico de influencias de particular sobre servidor público para obtener algún beneficio económico (art. 28); el delito de acuerdos restrictivos de la competencia en contratación estatal, ${ }^{32}$ delito inspirado de la alteración de la licitación pública por grupos empresariales que se distribuían secretamente la contratación administrativa, como lo conoció el país en el caso del grupo empresarial Nule. ${ }^{33}$ Igualmente, respecto del escándalo conocido como Agro ingreso seguro que para propiciar el desarrollo agrícola del país, terminó entregando subsidios públicos a latifundistas, una reina de belleza y hasta a un narcotraficante extraditado ${ }^{34}$ y los dineros no fueron utilizados para desarrollar el agro, la respuesta fue penal, a través de la creación del delito de fraude en subvenciones. ${ }^{35}$ Por último, el Estatuto de 2011 aumenta considerablemente las penas, entre otros, de delitos como el

y trabajadores del Estado y de sus entidades descentralizadas territorialmente y por servicios. Para los mismos efectos se considerarán servidores públicos, los miembros de la Fuerza Pública, los particulares que ejerzan funciones públicas en forma permanente o transitoria, los funcionarios y trabajadores del Banco de la República, los integrantes de la Comisión Nacional Ciudadana para la Lucha contra la Corrupción y las personas que administren los recursos de que trata el artículo 338 de la Constitución Política".

31 La norma "proporciona un esquema de servidor público mucho más amplio que el de uso común en derecho administrativo" (SANTOFIMIO, Jaime Orlando. Tratado de derecho administrativo - Contratación indebida. Bogotá: Universidad Externado de Colombia, 2004. t. IV. p. 70).

32 "El que en un proceso de licitación pública, subasta pública, selección abreviada o concurso se concertare con otro con el fin de alterar ilícitamente el procedimiento contractual [...]": art. 27 de la ley 1474 de 2011.

з3 “Tras 15 años de trayectoria, los dueños del denominado Grupo Nule conformaron un emporio como para dejar con la boca abierta a cualquiera: más de 35 empresas en los sectores de energía, agua y construcción; Ilegaron a participar en más de 86 consorcios para las diferentes licitaciones públicas; sus inversiones traspasaron las fronteras, además de varios países de América Latina desarrollaron proyectos en España, y en busca de recursos llegaron a China y Dubái. En su mejor momento facturaron más de 200 millones de dólares al año, y emplearon, directa e indirectamente a través de sus empresas, a unas 15.000 personas. Se convirtieron en las estrellas nacientes de la contratación pública del país" (LA CAÍDA del grupo Nule. Semana, 11 sept. 2010. Disponible en: <http://www.semana.com/nacion/articulo/la-caida-del-grupo-nule/121790-3>).

34 Uno de los beneficiarios del programa gubernamental fue el narcotraficante extraditado Ismael Pantoja Carrillo, alias el "Negro" (AGRO escándalo seguro. Semana, 13 oct. 2009. Disponible en: <http://www.semana.com/ nacion/articulo/agro-escandalo-seguro/108603-3>).

35 “Entre los comportamientos que aparentemente no encuadraban totalmente en las figuras tradicionales del código Penal se detectó el obtener indebidamente subvenciones del Estado, comportamiento que apareció de nuevo en el panorama nacional con la aprobación de los subsidios conocidos como de agro ingreso seguro (AIS), de los que fueron beneficiarios familias adineradas del país, los cuales no reunían cabalmente los requisitos para tal beneficio. Esta situación condujo a que, previa aceptación de los cargos, los responsables fueran condenados por delitos de peculado y falsedad en documento, cuando en verdad se trata de un típico fraude a subvenciones" (HERNÁNDEZ QUINTERO, Hernando A. El nuevo delito de fraude a subvenciones. Revista Derecho Penal y Criminología. Bogotá, v. 34, n. 96, p. 31-55, ene./jun. 2013). 
enriquecimiento ilícito del servidor público, el soborno transnacional y el peculado por aplicación oficial diferente o el peculado culposo cuando recaiga sobre recursos de la seguridad social.

\subsection{La sanción administrativa de la corrupción}

En materia administrativa - disciplinaria - el Estatuto de 2011 significó una ampliación en muchos aspectos: precisó los particulares que pueden ser objeto de sanción disciplinaria, artífices o sujetos de la corrupción (art. 44): el interventor, consultor y asesor en contratación estatal. Estos particulares completaron la lista en la que ya se encontraban los particulares que administran dineros o recursos públicos o ejercen función pública de manera permanente o transitoria. También se amplió la posibilidad de revocar los autos de archivo de procesos disciplinarios y los fallos absolutorios (art. 47-49). El término de caducidad de la acción disciplinaria fue considerablemente aumentado ya que no se tratará de 5 años contados desde la comisión de la falta hasta la adopción de la decisión de primera instancia, sino de 5 años para abrir la investigación disciplinaria. El término de la investigación disciplinaria fue ampliado de 6 a 12 meses. Se previeron nuevas faltas disciplinarias gravísimas aplicables a los interventores del contrato estatal tales como no exigir la calidad de bienes y de servicios, certificar como recibida a satisfacción una obra que en realidad no ha sido bien ejecutada y no informar sobre hechos de corrupción que puedan generar incumplimiento del objeto contractual.

El panorama sancionatorio podría dar la apariencia de un sistema en el que la amenaza de las sanciones, con su creciente violencia y su efecto disuasivo atemorizador -, son suficientes para erradicar o, al menos, controlar la corrupción. No obstante esta lógica, la realidad demuestra que los aparatos penales se encuentran necesariamente un paso atrás del ingenio corrupto y la historia de la tipificación pone en evidencia que el corrupto siempre es más ingenioso que el legislador, incluso cuando, como ocurre con frecuencia, corrupto y legislador son la misma persona. Por esta razón, frente al fenómeno de la corrupción, la segunda estrategia utilizada en Colombia es la que busca retrotraer los efectos de la corrupción.

\section{Revertir}

La sanción no revierte los efectos de la corrupción; sólo sacia las ansias de venganza privada y pretende educar a través del miedo. La resocialización y la protección del delincuente, en Colombia, son sofismas. No todos los efectos de la corrupción pueden ser retrotraídos: ni el daño a la imagen de las entidades públicas, ni la desconfianza de la población en las instituciones, ni la ineficacia e ineficiencia administrativas ya consolidadas. Por esta razón, la lucha contra la corrupción en 
Colombia busca revertir solamente los efectos patrimoniales de la misma, ${ }^{36}$ lo que pone en evidencia el carácter limitado, aunque necesario de estos mecanismos.

\subsection{Parte civil y extinción de dominio}

En primer lugar, el Estatuto anticorrupción de 1995 (ley 190) dispuso la obligación de constituir la parte civil del proceso penal en todos los procesos por delitos contra la Administración pública, ${ }^{37}$ sin que este instrumento sea incompatible con la atribución de responsabilidad fiscal por parte de la contraloría. ${ }^{38}$ También, en 1996 se creó la figura de la extinción de dominio de bienes producto de actividades ilícitas. Este instrumento ha sido regulado sucesivamente por la ley 333 de 1996, la ley 793 de 2002 y, actualmente, por la ley 1708 de 2014, "Código de la extinción de dominio" que la define como "una consecuencia patrimonial de actividades ilícitas o que deterioran gravemente la moral social, consistente en la declaración de titularidad a favor del Estado de los bienes a que se refiere esta ley, por sentencia, sin contraprestación ni compensación de naturaleza alguna para el afectado": art. 15. Aunque la extinción de dominio tiene una vocación amplia, ha sido utilizada con muy poco éxito y de manera limitada principalmente respecto de bienes obtenidos fruto del narcotráfico. En la persecución de los bienes fruto de la corrupción, el balance es decepcionante, ${ }^{39}$ aunque se trate de un instrumento interesante en la lucha contra la corrupción, en la medida en que el interés principal de los corruptos es el dinero y, en cierta medida, prefieren estar algunos años en prisión, siempre y cuando puedan, con posterioridad, gozar libremente de los frutos de su ilícito. ${ }^{40}$ Las sucesivas reformas

36 La Convención de Naciones Unidas contra la corrupción tiene un capítulo $\mathrm{V}$ dedicado a la recuperación de activos.

37 Para que sirva la sanción penal contra la corrupción es necesario que "esa condena y su ejecución incluyan la neutralización del beneficio económico, de manera que la norma penal, además de la función de prevención especial que se concentra en el reo, cumpla su función, más importante si cabe, de prevención general" (CONDE-PUMPIDO TOURÓN, Cándido. El poder público no atiende al interés general. In: MORELLI RICO, Sandra et alli (Coords.). Corrupción, flagelo mundial. Bogotá: Contraloría General de la República, 2013. p. 31. t. II).

38 “La atribución de la Contraloría General de la República contenida en el artículo 268-5 de la C.P., no trasciende el campo de la responsabilidad fiscal y se ejercita sin perjuicio de la acción penal correspondiente que, incluso, ése órgano puede promover ante las autoridades competentes (C.P. art. 268-8)": Corte constitucional, sentencia C-038-96.

39 “De acuerdo con una información solicitada por la Secretaría de Transparencia a la Fiscalía General de la Nación, durante los últimos 11 años en 594 procesos de extinción del derecho de dominio, derivados de casos de corrupción, fue decretada la inhibición en 338 de ellos, lo que significa que en el 57 por ciento de tales procesos no se encontró méritos para investigar" (ESTUDIARÁN mecanismos para aumentar eficacia de extinción de dominio. Presidencia de la República, Bogotá, 12 abr. 2013. Disponible en: <http://wsp. presidencia.gov.co/Prensa/2013/Abril/Paginas/20130412_03.aspx>).

40 “La Extinción de Dominio es una herramienta muy fuerte de lucha contra el narcotráfico, pero ahora debe convertirse en una herramienta de la lucha contra la corrupción. Los delincuentes dedicados a ese tema obtienen grandes sumas de dinero, y a veces poco les importa estar en la cárcel uno, dos, tres años o un periodo corto si salen ricos. Entonces ahí la extinción de dominio debe ser aplicada con más fuerza y decisión en la lucha contra la corrupción" (EXTINCIÓN de dominio deber ser la nueva herramienta contra corruptos. El Nuevo Siglo, 18 marzo 2012. Disponible en: <http://www.elnuevosiglo.com.co/articulos/3-2012-extinción-dedominio-deber-ser-la-nueva-herramienta-contra-corruptos-medell\%C3\%ADn.html>). 
han buscado hacer eficaz el procedimiento que, en promedio, ha tenido una duración de más de 10 años y, en una proporción importante, ha terminado sin sentencia de extinción por la habilidad de los abogados. El otro problema que aqueja la figura es la del manejo de los bienes fruto de la extinción del derecho de propiedad, ya que la entidad encargada de dicha administración se convirtió en un foco de corrupción en el país, a tal punto que varios de sus exfuncionarios enfrentan procesos penales ${ }^{41}$ y la entidad fue suprimida finalmente por el Decreto 3183 del 2 de septiembre de 2011 "Por el cual se suprime la Dirección Nacional de Estupefacientes, se ordena su liquidación y se dictan otras disposiciones".

\subsection{La responsabilidad fiscal}

Otro instrumento para revertir los efectos patrimoniales de la corrupción es la figura de la responsabilidad fiscal ${ }^{42}$ a cargo de las contralorías, autoridades administrativas independientes de control. Estas entidades realizan el control del gasto público y del manejo de los recursos públicos, ambiente natural de la corrupción. Para declarar las responsabilidades fiscales y ordenar el reembolso, las contralorías llevan a cabo juicios de responsabilidad fiscal que terminan con condenas si se comprueba, a más del detrimento patrimonial, la actuación con dolo o culpa grave por parte del gestor fiscal. En la pro de la lucha eficaz contra la corrupción, el Estatuto anticorrupción de 2011 previó unas situaciones en las que el dolo o la culpa grave del gestor fiscal se encuentran presumidos y, por lo tanto, se invierte la carga de la prueba hacia el investigado. Se trata de circunstancias de mala gestión administrativa, por ejemplo: elaborar pliegos de condiciones vagos o imprecisos, cuya interpretación o aplicación diera lugar a detrimento patrimonial; el incumplimiento de las obligaciones de interventoría, como no visitar las obras; el reconocimiento de salarios y prestaciones violando normas laborales de función pública, entre otras. Para garantizar el pago efectivo de la condena en responsabilidad fiscal, el Estatuto de 2011 dispuso una solidaridad legal entre el ordenador del gasto y el contratista y todos aquellos que participaron en la afectación del patrimonio público (art. 119, declarado constitucional por la sentencia C-388-14). Con el fin de generar eficiencia en el proceso de responsabilidad fiscal, el Estatuto creó un proceso verbal. Además, se creó un Grupo especial de reacción inmediata y de investigaciones especiales revestidos de poderes de policía judicial.

\footnotetext{
41 A IMPUTACIÓN 11 personas por caso DNE. El Espectador, 29 sep. 2011 Disponible en: <http://www. elespectador.com/noticias/judicial/imputacion-11-personas-caso-dne-articulo-302753>.

42 La responsabilidad fiscal está regulada en la ley 610 del 2000.
} 


\subsection{La acción de repetición y el llamamiento en garantía con fines de repetición}

La misma Constitución colombiana de 1991, en su artículo 90, prevé otro mecanismo para proteger el patrimonio público, en este caso, no de la mala gestión fiscal, sino de las condenas al Estado que resulten del dolo o de la culpa grave de sus agentes, formas naturales de la corrupción. La acción de repetición y el llamamiento en garantía se encuentran regulados en la ley 678 de 2001. La obligación de buscar el reembolso de lo pagado por la condena, conciliación o reconocimiento indemnizatorio recae sobre el jefe de la entidad obligada a pagar. El Estatuto anticorrupción de 2011 previó que de no iniciarse la acción de repetición por parte de la entidad condenada, la ejercerá el Ministerio de justicia y del Derecho a través de su Dirección de defensa judicial (art. 6).

Si los corruptos son privados de los frutos de la corrupción, a más de proteger el patrimonio público, la corrupción se desestimula. Sin embargo la extinción de dominio por actos de corrupción muestra resultados de éxito bastante bajos, no sólo por las prácticas dilatorias de los investigados, sino también por la corrupción misma de los órganos encargados de administrar los bienes retirados, mientras que la acción de repetición y la responsabilidad fiscal enfrentan un grave problema de eficacia por la insolvencia provocada de los corruptos, que impide ejecutar las decisiones de reembolso. Los paraísos fiscales, como lo es Panamá, ${ }^{43}$ son los principales obstáculos para la recuperación de los dineros públicos afectados por la corrupción ya que, al no compartir información financiera con Colombia, en nombre del secreto bancario, protegen las arcas de los corruptos. Frente a la impunidad de la persecución y la ineficacia de la reversión, ${ }^{44}$ a pesar de ser instrumentos preferidos en Colombia, es necesario utilizar instrumentos de prevención.

\footnotetext{
43 Los paraísos fiscales no han celebrado o cumplido las obligaciones de la Convención Multilateral de Asistencia Mutua en Materia Tributaria. Luego del fracaso de negociación directa con el Gobierno de Panamá para compartir información financiera, Colombia declaró como paraísos fiscales a Barbados, Emiratos Árabes Unidos, Kuwait, Qatar y Panamá, mediante el Decreto 1.966 del 7 de octubre de 2014. Por la presión del Gobierno de Panamá y, en busca de negociación, su inclusión en la lista de paraísos fiscales fue suspendida por Colombia, pero si no se llega a un acuerdo, se reactivará (PANAMÁ entra y 10 países salen de lista de paraísos fiscales. Portafolio. co, 8 oct. 2014. Disponible en: <http://www.portafolio.co/economia/panama-paraiso-fiscal-colombia>).

44 "este estatuto de responsabilidad fiscal tiene serios desajustes institucionales y jurídico- procesales, que exigen a las contralorías un profundo esfuerzo de cambio, dentro del marco de una nueva herramienta legal, si se quieren alcanzar los objetivos constitucionales asignados con los propósitos resarcitorios desde la perspectiva del ordenamiento jurídico, y de la lucha contra la corrupción, como componente implícito de los mismos" (AMAYA OLAYA, Uriel Alberto. Teoría de la responsabilidad fiscal. Bogotá: Universidad Externado de Colombia, 2002. p. 95).
} 


\section{Prevenir}

Es posible que los instrumentos para prevenir actos de corrupción no logren erradicarla por completo, ${ }^{45}$ pero pueden disminuirla progresivamente, transformar la regla en excepción, generar asombro en la sociedad, tristemente acostumbrada a la corrupción. Para hacer más difícil el desarrollo de la corrupción, el derecho administrativo utiliza el acceso a la función y el procedimiento administrativo. También se acude a la formulación de políticas públicas anticorrupción.

\subsection{El acceso a la función y al contrato}

El acceso a la función o al contrato es el primer elemento para prevenir la corrupción. La escogencia de los funcionarios públicos o de sus contratistas, si bien no apunta a la selección de ángeles exentos de tentaciones, sí busca dos objetivos: la escogencia de personas con un perfil adecuado para el ejercicio del cargo y la exclusión misma de la corrupción en la selección de agentes del Estado y de los contratistas. En cuanto a la escogencia de funcionarios, el primer elemento es la identificación de su habilidad legal para ejercer la función. La determinación de inhabilidades para ejercer cargos públicos se remonta al derecho indiano donde existió una prohibición de nombrar parientes en el cuarto grado de relación con un funcionario, criados o allegados de éste 0 deudores de la Real Hacienda. ${ }^{46}$ En la legislación colombiana actual, el Estatuto anticorrupción de 1995 previó la obligación de todo aspirante a un empleo público o a contratista del Estado de prestación de servicios de hacer una declaración de no estar incurso en situación alguna de inhabilidad o incompatibilidad (art. 1). Para evitar que la utilización de sociedades comerciales permita la disimulación de las inhabilidades, para eludirlas, el Estatuto de 1995 autoriza a realizar el levantamiento del velo societario, medida que permite identificar los socios de la persona jurídica. En materia de inhabilidades, el Estatuto de 1995 crea una inhabilidad para contratar con el Estado o ejercer funciones públicas para aquellas personas condenadas por delitos contra el patrimonio público, transitoria y con posibilidad de rehabilitación. Sin embargo, el art. 4 del Acto legislativo de 2009 que reformó el artículo 122 de la Constitución, convirtió esta inhabilidad en definitiva, de por vida, es decir, sin posibilidad de rehabilitación. ${ }^{47}$ Fue necesaria

\footnotetext{
45 "sino que exista en un grado que no genere disfunciones sensibles al sistema" (GALÁN GALÁN, Alfredo. Buena administración e instrumentos jurídicos de la lucha contra la corrupción. La experiencia española In: MORELLI RICO, Sandra et alli (Coords.). Corrupción, flagelo mundial. Bogotá: Contraloría General de la República, 2013. p. 38. t. II).

46 Cf. MARILUZ-URQUIJO, José-María. El agente de la administración pública en Indias. Buenos Aires: Instituto Internacional de Historia del Derecho Indiano e Instituto de Investigaciones de Historia del Derecho, 1998. p. 125.

47 "Sin perjuicio de las demás sanciones que establezca la ley, no podrán ser inscritos como candidatos a cargos de elección popular, ni elegidos, ni designados como servidores públicos, ni celebrar personalmente,
} 
una reforma constitucional para evitar la censura por contrariar la dignidad humana. El Estatuto anticorrupción de 2011 creó una inhabilidad especial para contratar con el Estado respecto de quienes incurran en actos de corrupción y dispuso que “[...] Esta inhabilidad se extenderá a las sociedades en las que sean socias tales personas, a sus matrices y a sus subordinadas, con excepción de las sociedades anónimas abiertas" (art. 1). Teniendo en cuenta la corrupción en la financiación de las campañas políticas y en las retribuciones a través de contratos administrativos, el Estatuto de 2011 creó una inhabilidad para contratar con la administración del nivel respectivo, respecto de quienes han financiado campañas políticas a la Presidencia de la República, las Gobernaciones o las Alcaldías, con aportes superiores al 2,5 del tope máximo permitido para la financiación. Esta inhabilidad rige durante todo el período del Presidente, del Gobernador o del Alcalde cuya campaña ha sido financiada por el inhabilitado (art. 2). La medida busca evitar la captura de las entidades públicas por parte de los capitales privados. También, para combatir la llamada puerta giratoria que, como germen de corrupción, permite que los servidores públicos, al terminar su función pública, trabajen para empresas privadas con el objeto de gestionar sus intereses ante las entidades en las que trabajaban, el Estatuto de 2011 incluye una prohibición especial para prestar servicios de asistencia, representación o asesoría en asuntos relacionados con las funciones propias del cargo que ejerció, hasta por el término de 2 años después de haber cesado en el cargo ${ }^{48}$ o respecto de empresas que fueron objeto de inspección, vigilancia o regulación por la entidad en la que ejerció sus funciones o, de manera definitiva, respecto de asuntos que conoció directamente en su calidad de servidor público (art. 3). Dicha prohibición fue acusada de inconstitucionalidad por afectar el derecho fundamental al trabajo, pero fue declara constitucional por la sentencia C-257-13 al considerarla una limitación justificada por fines constitucionales y proporcionada. En el mismo sentido, el Estatuto de 2011 previó una inhabilidad para que los ex empleados públicos del nivel directivo contraten con la entidad en la cual prestaron sus servicios $u$ otras del mismo nivel administrativo, durante los dos años siguientes a la cesación de sus funciones (art. 2). Esta inhabilidad pretende excluir la contratación a través de las influencias que permanecen aún después de haber dejado el cargo. Para evitar la neutralización de la interventoría de los contratos estatales porque los interventores, en el fondo, son

o por interpuesta persona, contratos con el Estado, quienes hayan sido condenados, en cualquier tiempo, por la comisión de delitos que afecten el patrimonio del Estado o quienes hayan sido condenados por delitos relacionados con la pertenencia, promoción o financiación de grupos armados ilegales, delitos de lesa humanidad o por narcotráfico en Colombia o en el exterior. Tampoco quien haya dado lugar, como servidores públicos, con su conducta dolosa o gravemente culposa, así calificada por sentencia ejecutoriada, a que el Estado sea condenado a una reparación patrimonial, salvo que asuma con cargo a su patrimonio el valor del daño".

48 El art. 35 de la ley 734 de 2002, Código disciplinario único, ya incluía dicha prohibición pero el término era de 1 año, declarada constitucional por la sentencia C-893-03. 
los mismos contratistas, como ocurrió en el caso del grupo empresarial Nule, ${ }^{49} \mathrm{el}$ Estatuto de 2011 previó una inhabilidad para celebrar contrato de interventoría para la persona, familiar o grupo que haya celebrado contrato de obra pública, concesión o suministro de medicamentos o alimentos y durante todo el plazo de ejecución y liquidación del contrato (art. 5). Por último, el mismo Estatuto de 2011, en su art. 90, creó una inhabilidad de 3 años para contratar respecto de los contratistas que ejecutan de manera defectuosa sus obligaciones, pero son suficientemente prudentes para no configurar un incumplimiento grave que dé lugar a la caducidad del contrato, con la inhabilidad de 5 años que trae aparejada. Se trata de la inhabilidad por el incumplimiento reiterado de contratos, lo que se mide por la imposición de 5 multas durante la vigencia fiscal, 2 declaratorias administrativas de incumplimiento 0 2 multas y una declaratoria de incumplimiento.

A pesar de que, en Colombia, la carrera administrativa sea el sistema general de administración del personal, (art. 125 de la Constitución), sistema de acceso, ascenso y permanencia en el cargo por razones de mérito, ${ }^{50}$ la realidad administrativa muestra que, en muchos casos, la obligación constitucional se burla por la no realización de los respectivos concursos para proveer los empleos. Tal fue el caso de la Procuraduría general de la Nación, cuyo jefe, el procurador general de la Nación, fue reelegido para un nuevo período en circunstancias con graves visos de corrupción, por el hecho de que varios de los congresistas que votaron en su favor, tenían cuotas burocráticas en la Procuraduría, en cargos cuya designación y continuidad dependían de la reelección del Procurador. ${ }^{51}$ El Procurador se resistía a realizar concursos para proveer cargos en la Procuraduría y pretendía continuar nombrando libremente a funcionarios, hasta que, a través de una tutela, la Corte constitucional lo obligó a la realización de los concursos. ${ }^{52}$ Frente a esta orden, el encargado de luchar contra la corrupción decidió instaurar un recurso de nulidad contra dicha sentencia, recurso que fue desestimado. Este ejemplo muestra que existe aún un campo importante para trabajar en la prevención de la corrupción y consiste en la regulación de los contratos de prestación de servicios profesionales, para que dicho instrumento necesario, no siga siendo una burla a la norma constitucional y genere nóminas paralelas en las entidades públicas. El sistema de formación de funcionarios públicos en entidades

\footnotetext{
49 Disponible en: <http://portal.canalrcn.com/noticias/los_nule_hac\%C3\%AD_las_obras_y_ten\%C3\%AD_la_ interventor\%C3\%AD_de_las_mismas $>$.

50 El sistema permite la "diferenciación entre política y Administración y la búsqueda constante de evitar a toda costa subjetividad en la provisión del grueso de puestos de trabajo dentro de la Administración" (RINCÓN CÓRDOBA, Jorge Iván. Derecho administrativo laboral. Bogotá: Universidad Externado de Colombia, 2009. p. 508).

51 ALEJANDRO Ordóñez: reelección controvertida. Semana, 1 dic. 2012. Disponible en: <http://www.semana. com/nacion/articulo/alejandro-ordonez-reeleccion-controvertida/268711-3>.

52 Corte constitucional, sentencia T-147-13.
} 
públicas de calidad ${ }^{53}$ y la selección a través de estas entidades, parece ser una opción en la discusión.

Por último, en lo que concierne al manejo de personal, el Estatuto de 1995 creó la obligación para los funcionarios al momento de ingresar al servicio y al momento de dejar el cargo, de realizar una declaración juramentada de su patrimonio (art. 1316). Ya en época colonial se puso en funcionamiento un procedimiento llamado Juicio de residencia que se realizaba al funcionario al momento de terminar sus funciones. Sin embargo, la historia demuestra que incluso los residenciadores negociaban la absolución del funcionario residenciado. ${ }^{54}$

\subsection{El procedimiento administrativo anticorrupción}

El procedimiento administrativo es un instrumento que, según su configuración, puede convertirse en un instrumento eficaz en la prevención de la corrupción. El primer elemento es la simplicidad de los trámites. La complejidad y demora de los trámites administrativos son el paraíso de los tramitadores y de los sobornos a funcionarios para agilizar o simplificar el procedimiento ${ }^{55}$. Es por eso que tanto el Estatuto de 1995, como el decreto 019 de 2012 y la Ley anti trámites (962 de 2005) suprimieron considerablemente los trámites considerados inútiles o excesivos y simplificaron procedimientos. El decreto de 2012 prohibió la exigencia de declaraciones extrajuicio, autenticaciones y declaraciones de supervivencia, en desarrollo de la presunción constitucional de Buena fe (art. 83 de la Const.). También prohibió solicitar documentos que reposan en la misma entidad, exigir la prueba de pagos realizados con anterioridad ante la misma administración para poder realizar trámites administrativos, rechazar solicitudes contenidas en formularios por errores de citas, de ortografía, de mecanografía, aritméticos o similares, exigir la representación de un abogado para la actuación administrativa y solicitar certificaciones de indicadores económicos para adelantar procesos o actuaciones ante las autoridades. Bajo la misma lógica, la ley de 2005 dispuso que todo requisito, para que sea exigible al administrado, deberá encontrarse inscrito en el Sistema Único de Información de Trámites, SUIT, que opera a través del Portal del Estado Colombiano, PEC,

\footnotetext{
53 La ESAP (Escuela superior de administración pública) también se ha visto envuelta en escándalos de corrupción, sin contar las controversias relativas a la calidad de la educación que ofrece (ARGÜELLO, Francisco. La ESAP: ¿desorganización y derroche de dinero? La Nación.com.co, 11 ago. 2013. Disponible en: <http://www.lanacion. com.co/index.php/noticias-regional/neiva/item/220918-la-esap-desorganizacion-y-derroche-de-dinero >).

54 HERZOG, Tamar. Ritos de control, prácticas de negociación: pesquisas, visitas y residencias y las relaciones entre Quito y Madrid (1650-1750). Madrid: Fundación Histórica Tavera, 2000.

55 “Los colombianos nos hemos acostumbrado a 'comprar' tiempo. Pagar a alguien, para que nos tramite algo más rápidamente, o para que se 'salte la cola'" (EXPOSICIÓN de motivos. Alcaldía Bogotá. Disponible en: <http://www.alcaldiabogota.gov.co/sisjur/normas/Norma1.jsp?i=10593\#0>. Acceso en: 20 oct. 2012).
} 
www.gobiernoenlinea.gov.co. De esta manera se hace más simple, objetivo y público el procedimiento administrativo y se reduce la necesidad de corrupción. Con el mismo objetivo, la informatización del procedimiento administrativo, al excluir la decisión individual, reduce también las oportunidades para la corrupción.

La opacidad y el desorden administrativo son el contexto ideal para la corrupción, la permiten y dificultan su puesta en evidencia, denuncia y persecución. Por esta razón, los corruptos desorganizan los procedimientos administrativos para que no pueda existir control sobre la toma de decisiones. En esta medida, la transparencia es el principal instrumento administrativo anticorrupción: ${ }^{56}$ "la luz del sol es el mejor de los desinfectantes". ${ }^{57}$ Bajo esta lógica, el Estatuto de 1995 previó sanciones disciplinarias para los servidores públicos que obstruyan la labor de los medios de comunicación o nieguen u obstruyan el acceso ciudadano a la información pública (art. 79). Además, ordenó la creación, en todas las entidades públicas del país, de oficinas de atención de peticiones, quejas y reclamos de los ciudadanos. Por su parte, el Código de procedimiento administrativo y de lo contencioso administrativo reguló, de manera amplia, el derecho de petición con fines de acceso a información y dicha regulación se encuentra hoy en día en la ley estatutaria de acceso a los documentos e información pública (ley 1712 de 2014) y en la ley estatutaria del derecho de petición (ley 1755 de 2015). Se trata de normas que establecen términos, obligaciones y procedimientos para controvertir las decisiones de negativa de acceso a la información que solamente puede tener por razón válida la reserva legislativa expresa.

En pro de la transparencia, el Estatuto de contratación estatal, ley 80 de 1993 y las normas complementarias, previeron mecanismos abiertos para la selección del contratista, como es el caso de la licitación pública y dispuso obligaciones como la publicación de los proyectos de pliegos de condiciones para la licitación, de los pliegos y de los contratos. ${ }^{58}$ El Estatuto de 2011 incluyó mecanismos de transparencia, incluso para la contratación sin licitación en mínima cuantía, (Art. 94): publicación de una invitación a ofrecer y un término reducido para recibir las ofertas.

\footnotetext{
56 Por esta razón resulta irónico que el Estatuto anticorrupción de 1995 sometiera a reserva los procesos disciplinarios, con otro tipo de argumentos: “Con el fin de evitar publicidad mal intencionada, que en nada ayuda a darle credibilidad al sistema judicial o disciplinario colombiano, se establece la reserva sobre los llamados pliegos o autos de cargos y se obliga a publicitar los fallos. En la actualidad, en la práctica se está condenando a la gente, sin que ésta siquiera haya tenido la oportunidad de ser escuchada en el proceso" (EXPOSICIÓN de motivos. Alcaldía Bogotá. Disponible en: <http://www.alcaldiabogota.gov.co/sisjur/normas/ Norma1.jsp? $\mathrm{i}=10593 \# 0>$. Acceso en: 20 oct. 2012). Esta norma quedó finalmente consagrada en el art. 33 de la ley 190 de 1995 que sólo excluyó de la reserva, el fallo disciplinario.

57 Louis Brandeis, juez de la Suprema Corte de los Estados Unidos, citado en GUICHOT, Emilio. El sentido, el contexto y la tramitación de la ley de transparencia, acceso a la información pública y buen gobierno. In: GUICHOT, Emilio (Coord.). Transparencia, acceso a la información pública y buen gobierno: Estudio de la Ley 19/2013, de 9 de diciembre. Madrid: Tecnos, 2014. p. 17.

58 Art. 19 decreto 1510 de 2013. Cf. Circular Externa № 1 de 21 de junio de 2013.
} 
La transparencia administrativa desarrolla un principio más general y opuesto a la corrupción que es la democracia. ${ }^{59}$ Por esta razón, el art. 32 del Estatuto de 2011 determina que todas las entidades públicas tienen la obligación de desarrollar sus funciones de acuerdo con los principios de democracia participativa, para lo cual, deben convocar a audiencias públicas, propiciar la participación ciudadana, fomentar las asociaciones de usuarios y ciudadanos y de control social de la actividad pública. Por último, obliga a la rendición periódica de cuentas ante la ciudadanía. ${ }^{60}$

Habiendo aprendido de las tristes experiencias de corrupción, como el caso del grupo Nule, el Estatuto de 2011, mejoró los procedimientos administrativos para prevenir la corrupción: en primer lugar prohibió la expedición de adendas o modificaciones al pliego de condiciones para la licitación dentro de los tres días anteriores al cierre previsto de la misma (art. 89). En segundo lugar, el Estatuto dispuso que el manejo de los dineros del anticipo para el contratista no sería libre por parte del particular, sino que deberá constituirse una fiducia pública que, como patrimonio autónomo, garantice la correcta inversión de los dineros públicos (art. 91). En tercer lugar, creó la figura de la supervisión del contrato que necesariamente debe ser desarrollada por un funcionario de la planta de la entidad contratante (art. 82), esto con el fin de corregir la situación en la que bastaba con la celebración de un contrato para la interventoría del contrato de obra, de concesión o de suministro, pero no existía algún funcionario encargado de la verificación de la ejecución del contrato y dicha función se descargaba en el tercero interventor. ${ }^{61}$

El sistema administrativo de precios de referencia para la contratación estatal SICE (sistema de información de la contratación estatal), creado por la ley 598 de 2000 , fue un intento loable, aunque fracasado de un procedimiento administrativo para precaver actos de corrupción. Se trató de una base de datos que buscaba apoyar a la Contraloría en su labor de control a través de la tabulación de los precios promedios de los bienes y servicios que podría contratar la Administración pública, por medio del Catálogo Único de Bienes y Servicios (Cubs) y del Registro Único de Precios de Referencia (Rupr). Adminsitrado por particulares, la inscripción de proveedores en el sistema y en sus catálogos de precios no era gratuita, lo que determinó que no fuera interesante para los proveedores de bienes y servicios inscribir sus precios y, por lo tanto, el sistema fue progresivamente quedando desactualizado e inservible. La ONG

\footnotetext{
59 "La corrupción nos preocupa porque amenaza la esencia misma de la democracia y la base de nuestra organización social” (CONDE-PUMPIDO TOURÓN, Cándido. El poder público no atiende al interés general. In: MORELLI RICO, Sandra et alli (Coords.). Corrupción, flagelo mundial. Bogotá: Contraloría General de la República, 2013. t. II. p. 27).

60 La política nacional de rendición de cuentas se encuentra formulada en el documento CONPES 3654 de 2010.

61 "Con el fin de proteger la moralidad administrativa, de prevenir la ocurrencia de actos de corrupción y de tutelar la transparencia de la actividad contractual, las entidades públicas están obligadas a vigilar permanentemente la correcta ejecución del objeto contratado [...]": art. 82 de la ley 1474 de 2011.
} 
transparencia por Colombia concluye que este sistema murió de muerte natural. ${ }^{62}$ La puesta en marcha del sistema tuvo un costo de 42 millones de dólares, de los que, 23 millones resultaron de un préstamo contratado con el Banco Interamericano de Desarrollo.

El procedimiento administrativo también puede prever instrumentos para combatir la corrupción ya generada. Este es el caso de la revocatoria del nombramiento o la terminación del contrato que el Estatuto de 1995 reguló (art 5) cuando el nombramiento o la celebración del contrato no haya respetado los requisitos para el ejercicio del cargo o la celebración del contrato. El art. 37 de la ley 433 de 1998 reguló la revocatoria del nombramiento cuando no se acrediten los requisitos para el empleo por haber aportado documentación falsa. En este caso, previo proceso penal o disciplinario, el funcionario será inhabilitado para ejercer funciones públicas por el término de 3 años. ${ }^{63}$ El art. 6 del Estatuto de 1995 previó la revocatoria del nombramiento cuando sobrevenga una situación de inhabilidad y no sea corregida o superada en el término de 3 meses.

La configuración de procedimientos adecuados, objetivos, transparentes, que permitan la participación ciudadana no es suficiente para prevenir actos de corrupción. El auto control o los procedimientos de control administrativo son necesarios para el mismo fin. Tal es el caso del control interno de gestión que, si bien su objetivo central no es la prevención de la corrupción, sino la eficacia administrativa, a través del acompañamiento de la ejecución de los planes, programas y proyectos, accesoriamente identifica nichos de corrupción, en tanto que son factores que obstaculizan la consecución de los fines de la entidad, es decir, ineficacia administrativa. El sistema de control interno de calidad, inspirado de la auditoría contable, fue creado por la ley 87 de 1993, para reemplazar el control previo y general respecto del gasto público, ejercido por las contralorías antes de la Constitución de $1991 .^{64}$ Esta ley fue reglamentada por el Decreto 1826 de 1994, modificado

\footnotetext{
62 “Algunos dicen que el Sice duró hasta que su capacidad instalada llegó a su tope, porque el sistema colapsó al no poder suministrar la información actualizada. De acuerdo con Marcela Restrepo, directora de asuntos públicos de Transparencia por Colombia, quien fungió como usuaria especial del sistema, el Sice 'nunca logró consolidar el Cubs, porque éste era un catálogo muy ambicioso donde para cada producto existía una clasificación, un código de acuerdo a la características del mismo. Era un universo muy amplio. A esto se le agrega que el sistema dejó de ser importante para la Contraloría General y se notaba que no existía dentro del órgano de control un liderazgo frente al tema. El Sice murió de muerte natural'" (DESCALABRO del SICE. El Espectador, 17 marzo 2012. Disponible en: <http://www.elespectador.com/impreso/negocios/articulo332911-descalabro-del-sice>. Acceso en: 22 oct. 2012).

63 Esta interpretación del procedimiento para la imposición de la inhabilidad, resultó de la constitucionalidad condicionada establecida por la Corte constitucional en la Sentencia C-631-96.

64 La exposición de motivos de la ley 87 de 1993 explica: “Entre los principios rectores que deben regir la administración pública y que fueron estudiados por la Comisión Quinta de la Asamblea Nacional Constituyente se propuso la eliminación del control previo por parte de la Contraloría General de la República y a su cambio, establecer un control interno ejercido por las mismas entidades [...] Al exigirse la presencia de sistemas de control interno, se dota a la Administración Pública de elementos para la evaluación y retroalimentación de su gestión fiscal, se fortalece el principio de responsabilidad en cabeza de administradores y se previene la
} 
por el 1547 de 2001. El control interno de gestión es el que propende por la realización de los principios de la función administrativa, previstos en el artículo 209 de la Constitución; eficiencia, eficacia, moralidad, economía, celeridad, etcétera. Este instrumento afrontaba el problema de neutralización ya que los jefes de las oficinas de control interno de calidad eran nombrados discrecionalmente por el jefe de cada entidad pública, lo que determinaba su ausencia de autonomía para poner en evidencia los incumplimientos, factores de ineficiencia o ineficacia y los actos de corrupción. ${ }^{65}$ Por esta razón, el Estatuto de 2011 dispuso que los jefes de las oficinas de control interno de calidad serían nombrados, en el nivel nacional, por el Presidente de la República y, en el nivel territorial, por la máxima autoridad administrativa de dicho nivel, entiéndase, el Gobernador o el Alcalde (art. 8 y 9). El Estatuto reforzó la obligación de rendir informes, de denunciar los posibles actos de corrupción, de publicar un informe cada 4 meses del estado de la entidad y de rendir un reporte al director del Departamento administrativo de la Presidencia de la República y a los organismos de control.

El derecho administrativo dispone de instrumentos para prevenir la corrupción, como quedó evidenciado, tanto en lo que concierne el acceso a las funciones y a los contratos, como en la configuración de un procedimiento administrativo simple, transparente y que realice los principios de la función administrativa. Ahora bien, la prevención de la corrupción no debe primar sobre la búsqueda de la eficacia administrativa, ya que no se trata de fines incompatibles. La experiencia colombiana demostró los fatales efectos de buscar erradicar la corrupción, aún al altísimo precio de la ineficacia. Se trata del Estatuto de contratación de 1983, decreto-ley 222, que configuró un procedimiento rígido para seleccionar contratistas, confuso y difícil por la exigencia de demasiados controles previos que se mostraron redundantes y no contribuyeron en nada a combatir la corrupción. La presunción de mala fe con la que fue diseñado este estatuto determinó la ausencia plena de discrecionalidad administrativa. Como resultado de su aplicación, las entidades públicas debían reunir tantos y tan difíciles requisitos y sobrepasar tantos controles, que no podían contratar y varias entidades públicas fueron llevadas a la parálisis o, al menos a sobrecostos. ${ }^{66}$

posible co-administración por parte de los control, facilitando a los distintos órganos del Estado decidir sobre la conveniencia y oportunidad de todos los actos inherentes al ejercicio del poder. Como resultado se logra una administración responsable y comprometida en la prevención del fraude, malgasto y abuso, enfocada a buscar la eficiencia y eficacia de su gestión desligándola de una función de control externo universal y redundante, permitiendo la independencia suficiente que deberá acudir a los organismos de control para el examen posterior que les compete, a la luz de la nueva Constitución Política".

65 Para luchar contra la corrupción es necesario el fortalecimiento de los órganos internos de control en cuanto al "robustecimiento de su independencia" (GALÁN GALÁN, Alfredo. Buena administración e instrumentos jurídicos de la lucha contra la corrupción. La experiencia española In: MORELLI RICO, Sandra et alli (Coords.). Corrupción, flagelo mundial. Bogotá: Contraloría General de la República, 2013. p. 44. t. II).

66 “En la práctica, el tiempo para cumplir con estos requisitos, que eran llamados de legalización y de perfeccionamiento, podía ser superior al de la fecha de ejecución del contrato, con un agravante de carácter 
Es justamente por estas razones que la ley 80 de 1993, Estatuto actual, configuró procedimientos menos detallados, suprimió requisitos y controles, con miras a la eficacia de la contratación y, en su lugar, estableció una normatividad de principios que guían los procedimientos administrativos de selección del contratista: selección objetiva, igualdad, economía, etcétera. Pero el problema no es únicamente de normas o procedimientos. Una parte importante de la prevención de la corrupción política.

\subsection{La política pública anticorrupción}

En la lógica invertida de los instrumentos colombianos en la lucha contra la corrupción, el último es la formulación de políticas públicas para la prevención de la misma. La asimilación corriente que existe en Colombia entre la política con la corrupción misma y el discurso sin efectos, ha determinado que frente a escándalos graves de corrupción, la población exija penas altas de prisión y nunca opte por la formulación de nuevas políticas públicas. Es por esto que, aunque en los distintos estatutos anticorrupción se hayan previsto instancias para la formulación de dichas políticas, dichos instrumentos hayan sido residuales. Tal es el caso de la Comisión nacional para la moralización (art. 62 del Estatuto de 2011), conformada por una lista amplia de funcionarios públicos ${ }^{67}$ y cuyo conjunto de funciones definen una política pública. ${ }^{68}$ También se establecen comisiones regionales de moralización, con las mismas funciones. Igualmente existe una Comisión nacional ciudadana para la lucha contra la corrupción de conformación también plural ${ }^{69}$ y con funciones también de diseño de políticas públicas. ${ }^{70}$ Se suma a este entramado institucional, un Programa presidencial de lucha contra la corrupción, con presupuesto propio para el diseño e implementación de políticas anticorrupción y la coordinación de la lucha internacional contra la corrupción. Por último, el Estatuto de 2011, dispuso la obligación de todas

presupuestario, ya que cuando se comenzaba a ejecutar el objeto contractual había que hacer modificaciones en el precio, por aumento de costos, lo que llevaba indefectiblemente a la celebración de contratos adicionales y prórrogas presupuestales, mecanismos que encarecían el objeto contractual" (EXPÓSITO VÉLEZ, Juan Carlos. La configuración del contrato de la Administración pública en Derecho colombiano y español. Bogotá: Universidad Externado de Colombia, 2003. p. 177).

67 Presidente de la República, Ministro del Interior y Justicia, Procurador General de La Nación, Contralor General de la República, Auditor General de la República, Presidentes del Senado y Cámara, Fiscal General de La Nación, Presidente Corte Suprema de Justicia, Presidente del Consejo de Estado, Director del Programa Presidencia, Alto Consejero para el Buen Gobierno y Defensor del Pueblo.

68 Velar por la aplicación del estatuto, Coordinar acciones conjuntas, Coordinar intercambio de información, Establecer indicadores de eficiencia, eficacia y transparencia, Adoptar estrategia anual, Promover participación ciudadana, Promover el control social, Coordinar actividades pedagógicas.

69 Gremios económicos, ONGs del tema, Universidades, Medios de Comunicación, Veedurías ciudadanas, Consejo Nacional de Planeación y Organizaciones Sindicales.

70 Velar por la aplicación del estatuto anticorrupción, Realizar informe de seguimiento, evaluación y recomendaciones a las políticas y planes, Impulsar campañas educativas de promoción de valores éticos, Promover Códigos de Conducta, Seguimiento a casos de impacto, Seguimiento a cabildeo y Denunciar los actos de corrupción. 
las entidades públicas, de todos los niveles, de crear anualmente, una estrategia de lucha contra la corrupción y de atención al ciudadano (art. 73), donde se establezca con dicha periodicidad, el mapa de riesgos de corrupción de la entidad en cuestión ${ }^{71}$ y las estrategias para evitarla y combatirla.

Ahora bien, la mejor política es la educación. Por esta razón, el Estatuto de 2011 dispuso que los colegios deben incluir estrategias de formación en convivencia pacífica, participación democrática, cultura de la legalidad y del cuidado de lo público. Igualmente, la educación a través de los medios de comunicación fue tomada en consideración a partir de la obligación de divulgación de campañas institucionales contra la corrupción en los medios públicos de comunicación (art. 80).

\section{Conclusión}

Colombia negocia actualmente un acuerdo de paz con la guerrilla de las FARC. Frente a la posibilidad de la conclusión de los acuerdos, para muchos colombianos la prioridad no es atacar las causas del conflicto, para prevenir la conformación de nuevos grupos guerrilleros, ni reparar a las víctimas, sino saciar su sed de venganza, con altas penas de prisión para los guerrilleros. La misma realidad de inversión de prioridades y de instrumentos fue radiografiada en este escrito en el caso de la corrupción. Personalmente, hubiera preferido construir una demostración en la que la primera parte fuera la de la prevención, la segunda la reversión y la última la sanción, pero la lógica y la razón hubieran ocultado la realidad: en Colombia, la sanción es la prima ratio y la prevención es la última, aunque esta patología, Colombia no es el único país que la padece. ${ }^{72}$

\section{The instruments against corruption in Colombia: from the ultima ratio to the absence of reason}

Abstract: Although corruption is not a phenomenon unique to Colombia, the country has struggled to fight it from different angles. Logic would indicate that the instruments must give priority to provide, first, for the prevention of corruption, secondly, by rolling back their negative effects and, thirdly, to punish the corrupt. This gradation of instruments results from the very ultima ratio of criminal sanction. However, Colombia's

\footnotetext{
71 "la catalogación de determinadas actividades que podríamos denominar "de riesgo", como, por ejemplo, la contratación pública, el otorgamiento o percepción de subvenciones, la realización de actividades sujetas a licencia o autorización administrativa, el manejo de fondos o instrumentos de crédito y de instrumentos bancarios de movimientos de activos" (CONDE-PUMPIDO TOURÓN, Cándido. El poder público no atiende al interés general. In: MORELLI RICO, Sandra et alli (Coords.). Corrupción, flagelo mundial. Bogotá: Contraloría General de la República, 2013. p. 28. t. II).

72 "El tema de la corrupción se asocia tradicionalmente con el derecho criminal, que prevé infracciones específicas en esta materia" (GARDINI, Gianluca. Lucha contra la corrupción y fortalecimiento de la ética pública. El nuevo Código de conducta para los funcionarios públicos (Italia). In: MORELLI RICO, Sandra et alli (Coords.). Corrupción, flagelo mundial. Bogotá: Contraloría General de la República, 2013. t. Il. p. 47; MERLONI, Francesco. Las más recientes políticas para combatir la corrupción en Italia van desde la represión penal (¿o punitiva?) hasta la adopción de medidas administrativas de prevención. In: MORELLI RICO, Sandra et alli (Coords.). Corrupción, flagelo mundial. Bogotá: Contraloría General de la República, 2013. p. 113 y ss. t. II).
} 
fight against corruption has shown a reversal of logic, in which the criminal sanction becomes the prima ratio against corruption and blindly and naively confident in its deterrent power, in a country where corrupt prison rather pay, provided further ensure the enjoyment of the fruits of the crime. In reality, the instruments of administrative law, from its proper configuration and use, can significantly reduce levels of corruption in Colombia, while contributing to the efficiency of public activity.

Keywords: Corruption. Colombia. Administrative law. Criminal law. Disciplinary law.

\section{Referencias}

A IMPUTACIÓN 11 personas por caso DNE. El Espectador, 29 sep. 2011 Disponible en: <http://www. elespectador.com/noticias/judicial/imputacion-11-personas-caso-dne-articulo-302753>.

AGRO escándalo seguro. Semana, 13 oct. 2009. Disponible en: <http://www.semana.com/nacion/ articulo/agro-escandalo-seguro/108603-3>.

ALEJANDRO Ordóñez: reelección controvertida. Semana, 1 dic. 2012. Disponible en: <http://www. semana.com/nacion/articulo/alejandro-ordonez-reeleccion-controvertida/268711-3>.

AMAYA OLAYA, Uriel Alberto. Teoría de la responsabilidad fiscal. Bogotá: Universidad Externado de Colombia, 2002.

ARGÜELLO, Francisco. La ESAP: ¿desorganización y derroche de dinero? La Nación.com.co, 11 ago. 2013. Disponible en: <http://www.lanacion.com.co/index.php/noticias-regional/neiva/item/220918la-esap-desorganizacion-y-derroche-de-dinero>.

CINCO mil niños mueren desnutridos en Colombia cada año. Semana, 27 mayo 2009. Disponible en: <http://www.semana.com/nacion/problemas-sociales/articulo/cinco-mil-ninos-mueren-desnutridoscolombia-cada-ano/103513-3>.

CONDE-PUMPIDO TOURÓN, Cándido. El poder público no atiende al interés general. In: MORELLI RICO, Sandra et alli (Coords.). Corrupción, flagelo mundial. Bogotá: Contraloría General de la República, 2013. t. II.

CORRUPTION Perceptions Index 2014: Results. Transparency International. Disponible en: <https:// www.transparency.org/cpi2014/results>.

CORTE condena a Arias a 17 años de cárcel; está prófugo en EE. UU. El Tiempo, 17 jul. 2014. Disponible en: <http://www.eltiempo.com/politica/justicia/condena-a-andres-felipe-arias-por-agroingreso-seguro/14260975>.

DESCALABRO del SICE. El Espectador, 17 marzo 2012. Disponible en: <http://www.elespectador. com/impreso/negocios/articulo-332911-descalabro-del-sice>.

DOWNLOAD 2015 Human Development Statistical Tables. United Nations Development Programme. Disponible en: <http://hdr.undp.org/en/data>.

DURKHEIM, Emile. De la division du travail social. Livre premier. Disponible en: <http://classiques. uqac.ca/classiques/Durkheim_emile/division_du_travail/division_travail_1.pdf>.

ESTUDIARÁN mecanismos para aumentar eficacia de extinción de dominio. Presidencia de la República, Bogotá, 12 abr. 2013. Disponible en: <http://wsp.presidencia.gov.co/Prensa/2013/ Abril/Paginas/20130412_03.aspx>.

EXPOSICIÓN de motivos. Alcaldía Bogotá. Disponible en: <http://www.alcaldiabogota.gov.co/sisjur/ normas/Norma1.jsp?i=10593\#0>. Acceso en: 20 oct. 2012. 
EXPÓSITO VÉLEZ, Juan Carlos. La configuración del contrato de la Administración pública en Derecho colombiano y español. Bogotá: Universidad Externado de Colombia, 2003.

EXTINCIÓN de dominio deber ser la nueva herramienta contra corruptos. El Nuevo Siglo, 18 marzo 2012. Disponible en: <http://www.elnuevosiglo.com.co/articulos/3-2012-extinción-de-dominio-deberser-la-nueva-herramienta-contra-corruptos-medell\%C3\%ADn.html>.

GALÁN GALÁN, Alfredo. Buena administración e instrumentos jurídicos de la lucha contra la corrupción. La experiencia española In: MORELLI RICO, Sandra et alli (Coords.). Corrupción, flagelo mundial. Bogotá: Contraloría General de la República, 2013. t. II.

GARDINI, Gianluca. Lucha contra la corrupción y fortalecimiento de la ética pública. El nuevo Código de conducta para los funcionarios públicos (Italia). In: MORELLI RICO, Sandra et alli (Coords.). Corrupción, flagelo mundial. Bogotá: Contraloría General de la República, 2013. t. II.

GUICHOT, Emilio. El sentido, el contexto y la tramitación de la ley de transparencia, acceso a la información pública y buen gobierno. In: GUICHOT, Emilio (Coord.). Transparencia, acceso a la información pública y buen gobierno: Estudio de la Ley 19/2013, de 9 de diciembre. Madrid: Tecnos, 2014.

HERNÁNDEZ QUINTERO, Hernando A. El nuevo delito de fraude a subvenciones. Revista Derecho Penal y Criminología. Bogotá, v. 34, n. 96, p. 31-55, ene./jun. 2013.

HERZOG, Tamar. Ritos de control, prácticas de negociación: pesquisas, visitas y residencias y las relaciones entre Quito y Madrid (1650-1750). Madrid: Fundación Histórica Tavera, 2000.

LA CAÍDA del grupo Nule. Semana, 11 sept. 2010. Disponible en: <http://www.semana.com/nacion/ articulo/la-caida-del-grupo-nule/121790-3>.

LA CAÍDA del imperio de los Nule. El Tiempo. Disponible en: <http://www.eltiempo.com/Multimedia/ infografia/nule/>.

MALA hora del gabinete Uribe. El Espectador, 30 jul. 2011 Disponible en: <http://www.elespectador. $\mathrm{com} /$ noticias/judicial/mala-hora-del-gabinete-uribe-articulo-288245>.

MARILUZ-URQUIJO, José-María. El agente de la administración pública en Indias. Buenos Aires: Instituto Internacional de Historia del Derecho Indiano e Instituto de Investigaciones de Historia del Derecho, 1998.

MEJÍA MAZUERA, Jaime. Barcazas no fueron bien aseguradas. El Tiempo, 10 feb. 1993. Disponible en: <http://www.eltiempo.com/archivo/documento/MAM-39133>.

MERLONI, Francesco. Las más recientes políticas para combatir la corrupción en Italia van desde la represión penal (¿o punitiva?) hasta la adopción de medidas administrativas de prevención. In: MORELLI RICO, Sandra et alli (Coords.). Corrupción, flagelo mundial. Bogotá: Contraloría General de la República, 2013. t. II.

ORDEN de captura a tres altísimos funcionarios del gobierno Uribe. Semana, 15 abr. 2015. Disponible en: <http://www.semana.com/nacion/articulo/sabas-pretelt-diego-palacio-alberto-velasquezcondenados-por-yidispolitica/424181-3>.

PANAMÁ entra y 10 países salen de lista de paraísos fiscales. Portafolio.co, 8 oct. 2014. Disponible en: <http://www.portafolio.co/economia/panama-paraiso-fiscal-colombia>.

PARRY, John H. The sale of public offices in Spanish indies under the Habsburgs. Berkeley; Los Angeles: University of California Press, 1953.

PIETSCHMANN, Herbert. Burocracia y corrupción en la Hispanoamérica colonial: Una aproximación tentativa. Editorial Nova Americana, Turín, n. 5, p. 11-37, 1982. 
PIETSCHMANN, Herbert. Corrupción en las Indias españolas. Revisión de un debate. In: GONZÁLEZ JIMÉNEZ, Manuel (Coord.). Instituciones y corrupción en la historia. Valladolid: Universidad de Valladolid, 1998.

RINCÓN CóRDOBA, Jorge Iván. Derecho administrativo laboral. Bogotá: Universidad Externado de Colombia, 2009.

SANTOFIMIO, Jaime Orlando. Tratado de derecho administrativo - Contratación indebida. Bogotá: Universidad Externado de Colombia, 2004. t. IV.

SANZ TAPIA, Ángel. La venta de oficios de hacienda en la Audiencia de Quito (1650-1700). Revista de Indias, v. XIII, n. 229, p. 633-648, 2003.

SILVA GARCÍA, Germán. Introducción: La corrupción a nivel mundial. In: MORELLI RICO, Sandra et alli (Coords.). Corrupción, flagelo mundial. Bogotá: Contraloría General de la República, 2013. t. II.

TENGO a los mejores investigadores. El Espectador, 8 oct. 2013. Disponible en: <http://www. elespectador.com/noticias/nacional/tengo-los-mejores-investigadores-articulo-439130>. Acceso en: 15 oct. 2013.

Informação bibliográfica deste texto, conforme a NBR 6023:2002 da Associação Brasileira de Normas Técnicas (ABNT):

OSPINA GARZÓN, Andrés Fernando. Instrumentos de la lucha contra la corrupción en Colombia: de la ultima ratio a la ausencia de razón. $A \& C$ - Revista de Direito Administrativo \& Constitucional, Belo Horizonte, ano 16, n. 63, p. 67-91, jan./ mar. 2016.

Recebido em: 22.08.2015

Aprovado em: 19.10.2015 